\title{
Por uma história renovada da febre amarela e da vacina antiamarilica no Brasil
}

\author{
For a new history of yellow fever and the yellow \\ fever vaccine in Brazil
}

\section{Claudio Bertolli Filho}

Universidade Estadual Paulista (Unesp), campus de Bauru Rua Albino Tâmbara, 9-16/63 Jardim Panorama 17011-230 Bauru — SP Brasil

cbertolli@uol.com.br

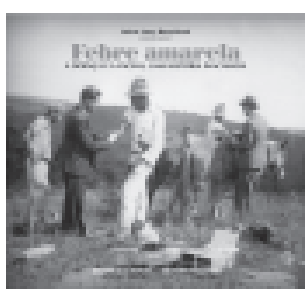

Febre amarela: a doença e a vacina, uma bistória inacabada Jaime Larry Benchimol (coord.) Rio de Janeiro, Bio-Manguinhos/ Editora Fiocruz, 2001, 469p.
A historiografia das doenças e das ciências médico-biológicas no Brasil ainda prima por realizar pesquisas que, de regra, isolam algumas poucas variáveis, na tarefa explicativa do objeto estudado, convergindo para a produção de versões simplificadoras e caricaturais da realidade científica e médico-sanitária nacional. Postando-se contra esta cômoda tendência, a obra coordenada por Jaime Larry Benchimol lança a cada página a seguinte questão de escopo teórico-metodológico: quais são os pilares científicos, organizacionais, políticos e sociais necessários para se arquitetar a história conseqüente de uma doença e de sua vacina?

Benchimol, que já nos premiou com outro estudo de envergadura (Dos micróbios aos mosquitos: febre amarela e revolução pasteuriana no Brasil, Rio de Janeiro, Fiocruz/Editora da UFRJ, 1999), volta à febre amarela, agora abordando a perspectiva da presença em "longa duração" da doença no Brasil e dos empenhos científicos, administrativos e políticos para controlar a disseminação da enfermidade pelo combate ao vetor e a obtenção de um imunoterápico eficiente. Nesta senda repleta de ramais e desvios, o ponto de partida da obra em pauta consiste no enfoque das primeiras menções à febre amarela como ameaça epidêmica no território brasileiro, datadas de meados do século XIX.

Ao chegar à capital do Império, a doença exigiu reações imediatas das esferas públicas e do agrupamento médico que, exprimindo a modernização ansiada pelas elites, cercou-se das respostas suportadas pela teoria miasmática e, em seguida, dos recursos conceituais e dos instrumentos laboratoriais fornecidos pelo ideário pasteuriano.

A articulação de uma estratégia médico-sanitária eficiente de intervenção no contexto social deu-se apenas nos primeiros anos do século XIX, não somente quando já se haviam acumulado indícios suficientes de que a febre amarela tinha como principal vetor o Aedes aegypti, mas também quando já ganhava novo direcionamento de pesquisa, no cenário nacional, o Instituto Soroterápico de Manguinhos, sob a direção de Oswaldo Cruz. 
O empenho republicano em sanear o Rio de Janeiro forneceu os apoios políticos e econômicos que viabilizaram as ações sanitárias que objetivavam, sobretudo, exterminar o mosquito responsável pela disseminação da febre amarela. Isso foi feito por meio da inspeção de residências e espaços públicos, na busca de ambientes favoráveis para a procriação do mosquito, além de dar combate a duas outras doenças que grassavam no antigo Distrito Federal: a varíola e a peste bubônica.

O viés autoritário assumido pela campanha de "civilização" do Rio de Janeiro somava-se aos receios populares em relação à atuação da corporação médica; ambas as situações foram catalisadas pelos críticos dos (des)caminhos assumidos pela jovem República, resultando, em 1904, no motim conhecido como a Revolta da Vacina, cujas implicações limitaram o alcance das medidas sanitárias que utilizavam o espaço carioca como uma espécie de área de teste das novas medidas higienistas que, em seguida, deveriam ser implantadas em outros pontos estratégicos do território nacional, inclusive nas áreas rurais de interesse econômico que se mostravam dominadas pela febre amarela.

O reconhecimento científico no estrangeiro das medidas inicialmente lideradas por Oswaldo Cruz não garantiu a continuidade do apoio das autoridades governamentais, que, em um posicionamento que se estende até hoje, têm se mantido reticentes, dando corpo a uma política pouco coerente em relação às instituições de pesquisas médicas. Dispondo de verbas nem sempre certas e geralmente bem abaixo das necessidades imediatas, feridos por baixos salários e também por sucessivas reorganizações burocráticas no setor da saúde pública, mesmo assim, os discípulos de Oswaldo Cruz mantiveram vivo o compromisso com a pesquisa, com o ensino e com a produção de quimioterápicos para um número cada vez maior de enfermidades. Desvelava-se assim a luta dos cientistas contra um quadro sanitário que impunha a definição do país como "um imenso hospital".

Estabelecidos os fundamentos nacionais da luta contra as enfermidades, um novo momento vislumbrado por Benchimol e sua equipe abriu-se com a presença no Brasil de uma missão médica patrocinada pela Fundação Rockefeller. Criada em 1913, nos Estados Unidos, por meio de uma aliança entre a Standart Oil e a Igreja Batista, já no ano seguinte, esta instituição delineou um programa de combate à febre amarela na América Latina como parte da proposta organizada por seu segmento médico de erradicação da doença em escala planetária. Estabelecidos no Brasil desde então, os representantes da fundação norte-americana encontraram de imediato forte oposição por parte da comunidade médica nacional, que vinha dando forma ao chamado "movimento sanitarista". Às acusações sobre as condições de ser o braço médico do imperialismo ianque e sobre o interesse dos estrangeiros de se servir da população brasileira como "cobaia", somavam-se ainda reclamos contra o monopólio das decisões por parte dos norte-americanos e insinuações segundo as quais os cientistas estrangeiros que atuavam na recém-criada Comissão contra a Febre Amarela estariam buscando desacreditar as pesquisas científicas que vinham sendo realizadas por seus pares brasileiros.

Nova frente de tensão deu-se quando os técnicos da Fundação Rockefeller, contrariando a estratégia empregada pelos sanitaristas 
tupiniquins, optaram pelo emprego de novos princípios na luta contra a febre amarela; em vez do combate extensivo ao vetor responsável pela doença, os norte-americanos centraram suas ações na teoria dos centros ou focos-chave, acreditando ser viável a erradicação da febre amarela intervindo-se em alguns centros endêmicos avaliados como disseminadores da enfermidade por amplos territórios. Além disso, em vez da tradicional fumigação dos prédios, adotou-se a colocação de peixes larvófagos, ou de uma camada de óleo nas águas suspeitas de servirem como criadouros de mosquitos. Criticados por não aderirem aos procedimentos empregados pelos sanitaristas brasileiros, os membros da Comissão Rockefeller declararam que as fumigações dos edifícios constituíam um mero "jogo de cena", mais apropriado para impressionar os incautos do que para erradicar os mosquitos.

A continuidade dos confrontos entre sanitaristas brasileiros e os enviados pela Comissão Rockefeller não parou por aí, ditando as possibilidades e os limites da luta contra o desafio amarílico. Os norteamericanos esforçaram-se por montar no Brasil uma admirável estrutura administrativa nos moldes tayloristas para coordenar e fiscalizar as atividades desenvolvidas por seus funcionários, pautadas por um rigoroso controle e quantificação das ações desempenhadas, com uma sanha nunca vislumbrada pelos brasileiros, o que gerou novas críticas. Confecção de mapas diários dos serviços realizados, periodicamente checados pelo funcionário que ocupava um cargo imediatamente superior na hierarquia, mapas estatísticos globais, relatórios escritos, fotografias dos ambientes visitados e imagens aéreas foram alguns dos recursos empregados pelos estrangeiros para melhor administrar a ameaça sanitária. Ao mesmo tempo, a Comissão contra a Febre Amarela deparou-se com a força do coronelismo; os potentados locais buscavam interferir nas ações sanitárias, impondo aos envolvidos a formação de pactos que pelo menos viabilizassem os trabalhos mais urgentes.

Em certos momentos do estudo aqui comentado, a análise volta-se para a história social, servindo-se de importantes dados sobre a reação popular à intervenção sanitária, fato que, embora tenha sido explorado por parte da historiografia sobre outras enfermidades, pouco ainda tem sido abordado no referente à febre amarela. Tomam-se como exemplo as situações que se multiplicaram a partir de 1931, quando, paralelamente às medidas antilarvárias, adotou-se a prática da viscerotomia com o objetivo de confirmar laboratorialmente os óbitos suspeitos pela enfermidade e, com isso, conferir maior confiabilidade aos inquéritos sanitários. Acontece porém que muitas famílias recusavam a permissão para tal prática nos cadáveres, havendo vários registros sobre o assassinato de médicos e de técnicos zelosos de seus deveres.

Para agilizar tais exames, a Comissão contra a Febre Amarela contava com dois laboratórios, um sediado na Bahia, que funcionou por alguns anos, e o de Manguinhos, que, a partir de 1937, passou a se responsabilizar por todos os exames no plano nacional. Como cada servidor passou a receber um pagamento suplementar para cada amostra visceral enviada ao Rio de Janeiro, os pesquisadores cariocas tiveram ainda de se defrontar com outro problema: o envio de pedaços de fígado de porcos como se fossem humanos, prática que tinha o objetivo de aumentar os salários dos técnicos de campo. 
Os servidores patrocinados pela Comissão Rockefeller retiraram-se da luta direta contra a febre amarela em meados da década de 1940, sendo que os norte-americanos centraram suas ações, a partir de 1942, no esforço de guerra que gerou o Serviço Especial de Saúde Pública. Nessa nova fase, muitos postos de controle da febre amarela foram fechados sumariamente, e os trabalhos de combate à enfermidade ficaram a cargo do Serviço Nacional da Febre Amarela, que fora criado em 1940. Desde seu nascimento, ele definiu-se como órgão totalmente controlado por sanitaristas brasileiros. Se o novo serviço assumiu os equipamentos, os laboratórios e o modelo organizacional trazidos pela Comissão Rockefeller, também herdou novos problemas: desde a década anterior, quando já não se verificavam mais epidemias urbanas de febre amarela, detectou-se uma nova ameaça: a variedade silvestre da doença, além da confirmação de que não só o Aedes aegypti, mas também outras variedades de mosquitos, além de alguns símios, atuavam como reservatório ou vetor da ameaça sanitária, fato que impunha novos e mais complexos procedimentos do controle a ser realizado pelos serviços de saúde.

Os novos desafios suscitados pela febre amarela exigiram a busca de novas respostas sanitárias. A partir de 1947, teve início o uso do DDT, aplicado segundo o método perifocal, que dava cabo do mosquito tanto em forma alada quanto aquática; juntava-se a isso a experiência adquirida pelos sanitaristas brasileiros que atuaram junto à Comissão Rockefeller e os arranjos, por vezes astuciosos, arquitetados pelos pesquisadores que atuavam nos laboratórios do Instituto Oswaldo Cruz (IOC). O resultado foi que, em meados da década de 1950, o Brasil foi declarado área livre do Aedes aegypti. Vivenciou-se, a partir de então, um período de erradicação transitória do principal vetor da febre amarela, fase que se estendeu até 1968.

A vitória passageira sobre o mosquito não ocorreu sem múltiplos impasses. Para além dos desafios técnicos e organizacionais, nova frente de tensões ganhou intensidade junto ao setor governamental. As seguidas reestruturações dos serviços de saúde e a troca dos titulares no Ministério da Saúde faziam com que a política do setor fosse alterada constantemente, impondo que os responsáveis pela luta contra a febre amarela dispendessem tempo e energia em negociações com a esfera política, em busca de recursos financeiros e viabilidade legal para dar continuidade aos serviços centrados no campus de Manguinhos.

Em um contexto pouco encorajador para o desenvolvimento de trabalhos, definiu-se um dos pontos vitais da luta contra a febre amarela: a obtenção de um imunoterápico eficiente contra a doença. Esse tema fora até então escassamente visitado pelos historiadores da febre amarela, mas os empenhos pela produção de uma vacina antiamarílica ganham tratamento privilegiado nas páginas coordenadas por Benchimol, abrindo caminho para um fascinante mundo a que, até então, mesmo os especialistas na história da medicina nacional tinham pouco acesso.

No contexto nacional, depois das iniciativas pioneiras de Domingos Freire, coube aos cientistas vinculados ao IOC dar prosseguimento às tentativas de obtenção de um imunizante contra a febre amarela, empenho que se redobrou a partir de 1928, quando uma violenta epidemia abateuse sobre o Rio de Janeiro, concomitantemente à comprovação final da 
ineficácia da vacina preparada por Hudeyo Noguchi, membro da Comissão Rockefeller. Em colaboração com os cientistas norte-americanos, os pesquisadores brasileiros sediados em Manguinhos tentaram um número relativamente grande de procedimentos complexos para produzir uma vacina eficiente, buscando obter um produto com maior poder imunizante e, ao mesmo tempo, com menos efeitos adversos.

Várias soluções foram testadas no decorrer da década de 1930, mas os resultados foram pouco animadores, com uma parcela dos vacinados não desenvolvendo a imunidade esperada contra a febre amarela ou apresentando urticária generalizada, hepatite e encefalite, sendo registrados alguns desenlaces fatais. Mais ainda, a suspeita de que os norte-americanos continuavam a utilizar os brasileiros como cobaias de suas experiências causava receios entre a população e mesmo entre algumas autoridades governamentais, favorecendo o comportamento da população em não se deixar inocular.

Nos laboratórios de Manguinhos, tudo parecia um grande enigma: como atenuar o vírus por passagem em diversos meios de cultura? Em que condições o micróbio deveria ser cultivado para a obtenção de uma cepa viável para a produção da vacina? Deveria ser empregado o soro humano ou o de cabra, ou, ainda, o de macaco, para a produção do imunizante? Estas e muitas outras questões tornaram-se motivo de pesquisas, assim como era testada a concepção de novos métodos, procedimentos e equipamentos laboratoriais, permitindo que, em certos momentos, caísse por terra a suposição de que a ciência produzida em um país periférico fosse mera reprodução do que era realizado nos laboratórios sediados nas nações com maior tradição em experimentos científicos.

Várias vacinas foram obtidas como resultado dos esforços do IOC; logo após a verificação de resultados abaixo do esperado, as equipes mobilizavam-se para buscar novas respostas para o desafio sanitário, e isso especialmente após a saída formal da Comissão Rockefeller da campanha contra a febre amarela. Ao mesmo tempo, para cada fracasso vacinal, reforçavam-se os programas de combate à febre amarela pela erradicação do mosquito vetor.

Na década de 1950, o Laboratório de Vacina Antiamarílica localizado em Manguinhos passou por seguidas transformações. Acompanhando o desenvolvimento de novas técnicas, fazia-se necessária a aquisição de equipamentos modernos e, com eles, delineava-se a necessidade de construção de novos edifícios para acomodar equipes, laboratórios e materiais. De nosso ponto de vista atual, tudo parece por demais artesanal; a escassez de verbas e a politicagem que de tempos em tempos intervinha nas pesquisas tinham como contrapartida a busca de soluções engenhosas e que demandavam o mínimo possível de recursos. Nessa complexa história, torna-se ainda mais surpreendente a posição brasileira como um dos mais produtivos centros de estudo e pesquisa no combate mundial à febre amarela.

O desenvolvimento da ciência e da tecnologia no período pós-guerra nutriram novas expectativas sobre a produção de um imunoterápico mais eficiente contra a febre amarela, originando novas questões a serem solucionadas, tais como a viabilidade de produção de vacinas sem o uso 
de soro, os critérios de estabelecimento da subcepa que deveria ser utilizada e a necessidade de uso laboratorial de ovos qualificados atualmente como SPF (livres de agentes infecciosos específicos) na produção do preventivo. O delineamento de um procedimento padrão a ser adotado na produção vacinal conta com uma longa e tortuosa história que implica a existência de uma linha de produção que exigia e continua a exigir atualização contínua do conhecimento e dos equipamentos e, mais do que isto, a constante luta contra agentes contaminantes dos produtos imunoterápicos. Mesmo não contando com uma parcela substancial dos equipamentos mais sofisticados, como, por exemplo, os que permitiam os processos de fermentação, definia-se a vocação de produção vacinal do IOC, ganhando destaque nesta fase a produção de vacina antivariólica que supria totalmente a demanda nacional e de alguns outros países, até 1972, quando a doença foi extinta em escala planetária.

Mesmo assim, a história parecia repetir-se: o trabalho dos cientistas brasileiros mostrava-se cada vez mais comprometido pela escassez de verbas para a pesquisa e pelos baixos salários pagos aos servidores. A partir de 1964, o Instituto Oswaldo Cruz sofreu um duro golpe, quando, por ordem dos generais-presidentes, procedeu-se à exclusão de importantes pesquisadores, no episódio que ficou conhecido como o Massacre de Manguinhos. O afã modernizador adotado pela ditadura não incluía, a princípio, a busca da autonomia nacional na produção de uma série de vacinas, enfatizando-se então as atuações curativas, em detrimento das iniciativas voltadas para a saúde coletiva.

Em conseqüência disso, o recrudescimento das epidemias de febre amarela, de dengue e, na década de 1970, a epidemia de meningite constituíram fatores de crítica acirrada ao regime, impondo uma revisão dos posicionamentos governamentais e, assim, viabilizando as primeiras providências para a reorganização do instituto, que se encontrava em tal estado de decadência que permitiu a um representante oficial avaliá-lo como um "cadáver insepulto". Como resultado, em maio de 1976, deu-se o desdobramento do Instituto de Produção e Distribuição de Medicamentos do Instituto Oswaldo Cruz em duas unidades independentes: Bio-Manguinhos, responsável pela produção de imunoterápicos, e Far-Manguinhos, voltado para a produção de quimioterápicos.

Bio-Manguinhos (cuja denominação oficial é Laboratório de Tecnologia em Produtos Biológicos de Manguinhos) incorporou-se ao Programa Nacional de Imunização, criado em 1973. Como peça estratégica na defesa da saúde pública, detectou-se a possibilidade de captação de recursos tanto internos quanto externos para a produção de imunoterápicos, sendo que, naquele momento, somente o Laboratório de Febre Amarela encontrava-se em condições de suprir a demanda do Ministério da Saúde. Paralelamente, percebeu-se também a necessidade de ampliação dos padrões de competitividade para garantir a penetração no mercado internacional, o que só poderia acontecer com o estabelecimento de parceria com empreendimentos laboratoriais de porte industrial.

Refletindo a conjuntura nacional, marcada inclusive pela aproximação econômica com o Japão, Bio-Manguinhos recebeu tecnologia e knowhow daquele país, e também de laboratórios franceses, para a produção de vacinas. A intenção de tornar-se uma empresa pública para a posterior 
associação com laboratórios nacionais e estrangeiros foi barrada na esfera política, inibindo a ampliação do poder nacional na produção de imunobiológicos.

Em paralelo à continuidade da recuperação física, de equipamentos e à expansão dos quadros do instituto, a década de 1980 foi marcada tanto por uma severa crise econômica quanto pelo incremento das doenças preveníveis, exigindo de Manguinhos a contínua expansão da capacidade produtiva de imunobiológicos. A posição central ocupada pela Fundação Oswaldo Cruz na defesa da saúde pública nacional coadunou-se com o objetivo governamental de estabelecimento de um programa de autosuficiência no setor vacinal. Nesse sentido, foi essencial um maior investimento oficial na modernização e nova expansão física das unidades produtoras.

Para ampliar as dificuldades, a revitalização de Manguinhos defrontavase com múltiplos desafios, que iam desde a sobrevivência de ranços do autoritarismo e dos feudos pessoais instalados nos laboratórios até a crítica desarticulação dos serviços. Somavam-se a isso, no período Collor, os boatos de que o 'Estado mínimo' iria demitir parcela considerável do pessoal lotado no instituto, fazer cortes nas já escassas verbas e promover a privatização do setor da saúde. A obsolescência do material e o desestímulo gerado pela conjuntura aliavam-se à política governamental sempre vacilante, condenando a Fiocruz, inclusive Bio-Manguinhos, a ser alvo fácil das críticas.

Neste cenário, parece surpreendente até mesmo para os autores da obra analisada o fato de a produção de vacina contra a febre amarela continuar sendo a mais bem-sucedida de Manguinhos, encontrando-se o instituto capacitado para responder positivamente aos novos surtos de febre amarela silvestre e de dengue que marcaram o período. Mesmo assim, a expansão da área epizoótica da febre amarela tornava urgentes as medidas de modernização dos laboratórios, a criação de novas estratégias de preparação, o controle de qualidade para evitar novos óbitos de vacinados e também o desenvolvimento de pesquisas voltadas para a produção de imunobiológicos pelo emprego de cultura de tecido de embrião de galinha, além das questões mais recentes pautadas pelos novos desafios propostos pela revolução fomentada pela biologia molecular. Define-se então o caráter sempre inacabado do envolvimento nacional com a febre amarela, princípio que instrui o próprio título conferido ao texto aqui comentado.

A dimensão multifacetada do livro coordenado por Jaime Benchimol aponta para a própria complexidade do tema e das estruturas mobilizadas para o delineamento de uma história consistente e inovadora da febre amarela e da produção da vacina antiamarílica. Consistente porque a análise baseia-se na interdependência das estruturas e da prática científica, afastando-se dos velhos esquemas que vislumbram a ciência como atividade autônoma, neutra em relação à trama social e poderosa $\mathrm{O}$ suficiente para não se deixar tocar por interesses políticos e econômicos. Inovadora porque, além da profundidade com que o tema foi explorado, lança novas luzes sobre o presente e o porvir da ciência nacional.

Como resultado, o leitor encontra-se diante de uma obra ímpar, uma história que não é expressa somente por palavras, mas também por um 
rico acervo fotográfico que exigiu da equipe intensa pesquisa no Brasil e no exterior, inclusive nos arquivos da Fundação Rockefeller, o que reforça a posição de destaque do livro na historiografia médica nacional, ensinando e fascinando a todos os interessados na história da medicina brasileira.

As lições oferecidas pelo texto são muitas, justificando inclusive a extensão desta resenha. Uma das lições que o livro nos oferece é que, apesar das adversidades em série fomentadas pelo desafio da febre amarela, pela ingerência tantas vezes deletéria da política no setor da saúde e pelo complexo quadro em que historicamente se encontra a saúde pública nacional, Benchimol e sua equipe mostram-se tão otimistas quanto sóbrios em suas avaliações, reproduzindo, na empreitada de um estudo histórico, uma das principais marcas definidoras do espírito científico vigente na maior parte da comunidade dos pesquisadores brasileiros. 